\section{Dentists warn failure to support self-employed may have devastating impact on service}

The British Dental Association (BDA) has warned meanstesting of support for the self-employed during the Coronavirus (COVID-19) crisis will have a potentially catastrophic impact on large parts of the dental workforce, particularly those providing private care.

While support measures are being put in place for NHS contract holders, the vast majority of high street dentists operate 'mixed' practices combining elements of state and private care.

While practice owners may be able to benefit from some relief via support for businesses, the self-employed associate dentists working under them are likely to be hit hard. Those operating exclusively on a private basis are thus far ineligible for any packages of support for lost income, beyond mortgage holidays and self-assessment deferrals for income tax.

The BDA estimate spending on private sector dentistry has exceeded the total UK-wide NHS budget since 2012. It warned an already threadbare NHS service would be incapable of meeting patient demand left by any fall in private capacity.

Chair of the BDA's General Dental Practice Committee Dave Cottam said: 'Many self-employed dentists working in largely or exclusively private practice have seen their incomes fall to zero.

'Failure to offer them a safety net will not only hit highly skilled individuals, but will have a devastating impact on the essential services they provide.

'When NHS dentistry is already stretched to breaking point, letting private practices go to the wall would be criminally irresponsible.'

\section{BDA calls on government for concrete support}

On 25 March the British Dental Association (BDA) called on government to offer concrete support for a new dedicated emergency dental system, as routine care on the high street ended following the latest guidelines from NHS England: https:// bit.ly/39xx6iJ.

England was the last UK nation to adopt this approach. The BDA had already advised its membership against routine treatment to reduce the risk of infection to both staff and patients.

NHS England has also set out plans to devolve the establishment of a dedicated Urgent Dental Care System to local level. The BDA has said that this will require proper support, resourcing and unfettered access to relevant Personal Protective Equipment (PPE) to cater for a potentially large number of higher-risk patients requiring treatment.

British Dental Association Chair Mick Armstrong said: 'Routine dental care as we know it is over for now. For the safety of dentists and their patients this is the right approach.

'Real energy must now be devoted to developing emergency services. Precious time has already been lost for planning, and colleagues will require the resources to provide it safely.

'The thousands who experience a dental emergency each day must not end up with another postcode lottery of provision.

'This profession stands ready and willing to support the national effort to fight this pandemic.'

For up to date news and information on the COVID-19 pandemic please visit the BDA website: https://www.bda.org/ advice/Coronavirus/.

\title{
Atapeurca hominids' tooth enamel grew faster than ours
}

Research published by the Dental Anthropology Group of the Centro Nacional de Investigación sobre la Evolución Humana (CENIEH) shows that the tooth enamel of the Atapeurca hominids grew faster than in modern humans. ${ }^{1}$

The study counted, for the first time, the two types of growth lines observed in the tooth enamel of Lower and Middle Pleistocene hominids in Europe. The investigation focused in particular on the species recognised at sites in the Sierra de Atapuerca. The results indicate that the growth rate of the enamel in these hominids could have been up to $25 \%$ faster than in Homo sapiens.

This work, in which New York University and University College London as well as other institutions also participated, studied in minute detail the formation of enamel in the Atapuerca hominids, both at the sites of Sima del Elefante (1.2 million years), Gran Dolina-TD6 (Homo antecessor: 850,000 years) and Sima de los Huesos (430,000 years), in addition to a fairly extensive collection of Homo sapiens teeth.

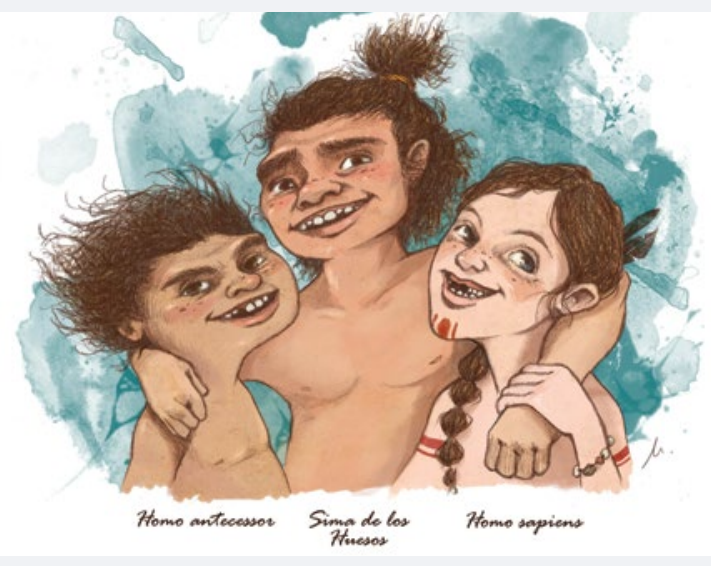

Credit: Illustration by Maria de la Fuente Soro

\section{Reference}

1. Modesto-Mata M, Dean M C, Lacruz R S et al. Short and long period growth markers of enamel formation distinguish European Pleistocene Hominins. Sci Rep 2020; 10: 4665. DOI: 10.1038/s41598-020-61659-y. 